\title{
EPISTEMOLOGIA DAS POSSIBILIDADES EDUCATIVAS: RECONSTRUIR O CONHECIMENTO PEDAGÓGICO
}

\author{
Ernesto Candeias Martins*
}

\begin{abstract}
RESUMO
As teorias da educação não têm dado muita atenção aos fenómenos e às questões de prática pedagógica nos diversos contextos educativos, pois há uma falta de enquadramento nas estruturas ordenadas e coerentes e de fundamentação epistemológica, devido à complexidade, ao caos e à falta de um estatuto teórico mais adaptado a essas novas situações de prática pedagógica actuais. Desde a complexidade educativa haverá que reconstruir o conhecimento pedagógico, reconduzindo a aprendizagem dos alunos a novas práticas (aprendizagem de labirinto, aprendizagem interpretativa, aprendizagem criativa, autogestão educativa, investigação-acção, hipertexto, educação ambiental, etc.). O autor admite a possibilidade de novas teorizações sobre a educação (reconstrução das teorias da educação) ajustadas às características de educabilidade e da educação/formação dos novos públicos. O futuro estará no equilíbrio entre a escola real e a escola virtual, porque a complexidade é simultaneamente real e virtual, de modo que a escola hipertextual e criativa se transforme numa estrutura social baseada em redes, promotoras de inovação e criatividade nos alunos.
\end{abstract}

PALAVRAS-CHAVE: Epistemologia. Saber pedagógico. Possibilismo. Teoria da Educação. Conhecimento pedagógico. Práticas Educativas. Hipertexto.

* Doutor em Ciências da Educação e Professor-Adjunto na Escola Superior de Educação do Instituto Politécnico de Castelo Branco/Portugal.

Educ. e Filos., Uberlândia, v. 21, n. 41, p. 89-120, jan./jun. 2007. 


\begin{abstract}
The theories of the education have not paid much attention to the phenomenon and the questions in service training, in the diverse educative contexts, therefore there is a lack of framework in the ordered and coherent structures and of epistemological framework, due to complexity, to the chaos and the lack of an adapted theoretical statute more to these new situations of in service teacher training nowadays. Since the educative complex there have to be to reconstruct the pedagogical knowledge, leading back the learning of the pupils new the practical ones (learning of labyrinth, interpretative learning, creative learning, educative self management, inquiry-share, hypertext, educational environments, etc.). The author admits the possibility of new theories on education (reconstruction of the theories of education) adjusted to the characteristics of educability and the education / training of the new public. The future will be in the balance between the real school and the virtual school, because of the complexity that is simultaneously real and virtual, in way that the hypertext and creative school if transforms into an established social structure in nets, promoters of innovation and creativity in the pupils.
\end{abstract}

KEYWORDS: Epistemology. To know pedagogical. Possibility. Theory of the education. Pedagogical knowledge. Practical educative. Hypertext.

Nunca penso no futuro. Ele chega demasiado cedo.

(A. Einstein)

Não temos bem a certeza se uma das questões centrais na actualidade, no âmbito do conhecimento pedagógico, se reduz ao simples debate das novas epistemologias, de uma 'nova' pedagogia, de novos modelos educativos ou da 'refundação da escola'. Esta forma de questionamento que, por vezes, é impregnada de

Educ. e Filos., Uberlândia, v. 21, n. 41, p. 89-120, jan./jun. 2007 
metáforas simples, ajuda os filósofos e os teóricos da educação a ver e a compreender melhor a realidade educativa em si mesmo, nesta era da globalização, da sociedade do conhecimento e da informação, que exige uma cultura global, social e institucional, desde do novo paradigma sócio-cognitivo humanista.

Atrevemo-nos mesmo a afirmar que as teorias e as ideias sobre a educação pecam, no contexto da complexidade, por falta de fundamentação, apesar de muitos dos seus contributos educativos e pedagógicos conterem alguma profundidade nos seus fundamentos. Sabemos que qualquer teoria educativa se caracteriza por ser sistemática, fundamental, geral, tendo na ordem, na estrutura, na linearidade e nos seus estereótipos a sua vigência ou a sua razão de ser. Por isso, o discurso teórico resultante, mais ou menos coerente, sempre se apoiou em subjectivismos morais e filosóficos, típicos de algumas escolas ou correntes de pensamento que foram dando autoridade às teorias sobre a educação (DOMENACH, 1995, p. 11-17).

É verdade que certas teorias educativas não deram muita atenção a alguns fenómenos ou a determinadas questões educativas concretas ou práticas, já que estes não se encaixavam nas suas estruturas coerentes e ordenadas. Por exemplo, para explicar a realidade das salas de aula, as teorias fogem às questões que não eram contempladas nos pressupostos teóricos criados. Por exemplo, os fenómenos quotidianos como o insucesso escolar, a indisciplina e a violência escolar, o comportamento e as atitudes dos alunos, a inadaptação situacional de alguns métodos, a problemática da sobredotação, etc., não tiveram um enquadramento adequado em muitas teorias pedagógicas (HUNTER \& BENSON, 1997, p. 9096).

De facto, a teoria da educação refere-se mais aos aspectos de interesse das escolas/correntes filosóficas ou epistemológicas que lhes servem de fundamento, que à própria realidade $\mathrm{e} / \mathrm{ou}$ contextos a que se refere. É por este facto que a complexidade e a desordem na educação ao nível da prática, desautorizam a teoria educativa, oferecendo-lhe paradoxalmente a(s) possibilidade(s) de reconstruir o próprio conhecimento, como indica Hargreaves (2003). 
Se criticamos uma teoria educativa, logo de imediato surge a possibilidade de novas teorizações adaptadas às características próprias da educabilidade e da educação, aos novos contextos e exigências dos novos públicos. O significado de uma mudança no momento de compreender o acto educativo pode ser vista desde a desordem, a complexidade e a dialéctica continuada da 'ordem/ desordem'. Esta situação de complexidade faz destruir a teoria educativa e, simultaneamente, permite uma nova construção do conhecimento pedagógico adaptado aos novos contextos da realidade educativa e da educação/formação actual.

Utilizamos a designação de desconstrução de uma teoria educativa, para de seguida podermos reconstruir uma teoria mais adaptada a esses contextos de complexidade, tornando-a numa teoria possível, numa possibilidade educativa (possibilismo), num modo disponível de procedimentos regulados aplicado à prática, metodologias de caminhos possíveis. Por isso, a desconstrução levanos à experiência do 'impossível', na terminologia de J. Derrida (1987, p. 11-20), a uma experiência do outro como invenção do impossível, entendendo essa possibilidade do possível, sempre que seja uma condição de possibilidade, como simples iniciação possível ou simples actualização do que já é possível. ${ }^{1}$

Para além da falta de fundamentação epistemológica na educação, causada por essa desordem e complexidade educativa, também há falta de um estatuto teórico adaptado a essa nossa situação da prática educativa. A educação deverá ser pensada e deverá ser realizada. Esta simples questão leva-nos à possibilidade

1 Para J. Derrida (2001, p. 302-306) não existe uma contradição lógica entre o possível e o impossível. De facto, o impossível não é o contrário do possível, nem a sua modalidade negativa, é a condição de possibilidade do possível. Quando o impossível se converte em possível, o acontecimento que tem lugar é a possibilidade do impossível, uma forma paradoxa do acontecimento. Ou seja, se um acontecimento ou uma teoria é possível (condições de possibilidade: explicação, desvelar, revelar, realizar o que já era possível) em novos contextos. Assim, para que um acontecimento, uma teoria seja possível na prática é preciso que seja como condição de evidência.

Educ. e Filos., Uberlândia, v. 21, n. 41, p. 89-120, jan./jun. 2007. 
de um divórcio entre a questão teórica e a questão prática, bem referidas em A. J. Colom (1986) e Jones (1994).

A teoria e a prática educativa seguem caminhos diferentes, sem encontro, a partir dos mesmos níveis em que se cria o conhecimento educativo. Essa relação desvirtua-se devido a alguns normativos legais, algumas estruturas administrativas e burocráticas do sistema educativo e das escolas que condicionam, por vezes, a génese e a aplicação do saber educativo. Alguns teóricos contemplam os posicionamentos teóricos da educação, esquivandose às referências práticas, da mesma maneira que alguns investigadores educacionais da realidade da sala de aula não possuem o mínimo interesse em posicionar as suas propostas em contextos teóricos. De facto, o enfoque da pesquisa educativa ou se focaliza para as questões teóricas ou bem para as práticas, de tal modo que temos teóricos que não praticam, como também há práticos que não teorizam ou conceptualizam.

É necessário retomar uma nova lógica para evitarmos esse desvio pedagógico existente no quotidiano das escolas. Deve surgir um novo alicerce de reflexão para a teoria e para a prática, de modo a dar-se uma mútua implicação. Sabemos que a educação deve ser pensada, questionada, havendo níveis de coerência entre a acção e o pensamento. Essa nova plataforma teórica deve permitir uma construção do conhecimento educativo e uma prática pedagógica centrada nas aprendizagens em contextos diversificados.

Esta possibilidade epistemológica implica uma nova construção do saber pedagógico, desde o conhecimento da criança, do aluno, desde as experiências e vivências educativas. Para tal haverá que transformar alguns postulados ou modelos em processos de acção ou intervenção educativa.

Abordaremos nesta nossa reflexão um quarteto de aspectos educativos, derivados da ruptura epistemológica da desconstrução do conhecimento (educativo, pedagógico), e posteriormente a construção de um novo conhecimento mais adaptado ao aluno, aos modelos de aprendizagem (aprender a aprender) em contextos diversificados e a um novo modelo de escola ('refundação da escola' na sua cultura e estrutura de organização), na sociedade actual. 
A nossa análise começará, em primeiro lugar, por uma incursão na conceptualização do saber pedagógico no âmbito da teoria da educação, e, em segundo lugar, faremos uma repercussão sobre o sentido da teoria da educação. Em terceiro lugar, argumentaremos sobre a possibilidade de construção do conhecimento pedagógico e, por último, faremos a apresentação de novas práticas educativas para a escola, salvaguardando a importância da criatividade e do hipertexto. Terminaremos realizando um envolvimento epistemológico, em que propomos algumas perspectivas de futuro para a educação.

Em suma, necessitamos de desconstruir a(s) teoria(s) para, simultaneamente, permitir uma nova construção do conhecimento pedagógico. Esta é uma das questões do nosso estudo: que possibilidades educativas se apresentam hoje para essa falta de fundamentação epistemológica na educação, causada por essa desordem e complexidade ou por falta de um estatuto teórico adaptado aos novos discursos, às novas linguagens e situações da realidade educativa na sociedade do conhecimento ou da informação (digital).

\section{A conceptualização do 'saber' na teoria da educação}

É no século XVIII que encontramos a referência da Pedagogia aplicada ao 'saber' (racional, especulativo, normativo e experiências), sobre a educação. ${ }^{2}$ Nos começos, a "Pedagogia" tratou de tudo o que era referente à educação, constituindo-se num saber teórico e prático, relacionado institucionalmente com a educação na escola, família e na comunidade. Nos princípios do século XX surge a primeira fragmentação, de índole metodológica (perspectiva de enfoque), desse "todo sobre a educação" que abordava a Pedagogia (ou ciência da educação).

2 Cremos que foi E. Kant quem utilizou, pela primeira vez, nos seus primeiros cursos universitários (1776), a 'Pedagogia' como conhecimento ou reflexão da educação. Mais tarde Trapp (catedrático de 'Pedagogia' em Halle), os discípulos de Bassedow (filantrópicos), Nyemeyer e Herbart configuraram uma estrutura ordenada e sistematizada do 'conhecimento pedagógico' sobre a educação.

Educ. e Filos., Uberlândia, v. 21, n. 41, p. 89-120, jan./jun. 2007. 
De facto, da aplicação do método experimental surge a 'pedagogia experimental' (LAY, NEUMANN), na tentativa de dar ao saber educativo a base do método científico, e de entendermos a realidade educativa a partir da reflexão e da racionalização especulativa, na linha de Herbart e de E. Planchard (uma 'Pedagogia Geral' como integradora das ideias gerais sobre a educação), da 'pedagogia racional' (PAULSEN), no uso metodológico de elaboração dos saberes educativos, da 'pedagogia fundamental' (COHN) ou da 'pedagogia essencial' (GÖTTLER, HENZ), na intenção de informar da coerência lógica do saber educativo e, ainda, da 'pedagogia crítica', ao submeter a revisão crítica o corpo de conhecimentos educativos ou pedagógicos.

Em todas essas denominações emergentes houve a pretensão, por um lado, de apresentar o conhecimento sobre a educação como um modelo educativo fundamentado e válido para o ser humano e, por outro lado, a distinção metodológica na elaboração da pedagogia experimental (CASTILLEJO \& COLOM, 1987, p. 1317; MOLES, 1995, p. 20-26).

A partir da década de 1930 do século passado originou-se outra fragmentação do corpo de conhecimentos da Pedagogia, afectando o saber pedagógico (conteúdos). É que as diferentes Ciências Sociais e Humanas, em pleno desenvolvimento, consideraram a educação como um espaço de estudo, pelo que a psicologia, a sociologia, a filosofia, a antropologia, a economia, etc., afectaram com os seus contributos o conhecimento da educação e paralelamente outras ciências (biologia, medicina, psiquiatria, ecologia, direito etc.) adaptaram os seus enfoques ao saber educativo.

A meados do séc. XX o saber pedagógico encontra-se nas mãos das ciências da educação, constituindo-se um conjunto múltiplo de disciplinas próprias (didáctica, organização escolar, história da educação, orientação escolar e profissional, etc.) que estudam aspectos particulares da educação que antes eram tratados pela Pedagogia. Esta denominação de 'Ciências da Educação' centralizou-se de modo analítico e plural no mesmo objecto de conhecimento - a educação. Esta mudança provocou transformações metodológicas, em que a reflexão conceptual da

Educ. e Filos., Uberlândia, v. 21, n. 41, p. 89-120, jan./jun. 2007. 
Pedagogia passou a ter um tratamento plurimetodológico das Ciências da Educação, tal como afirmam J. Sarramona e S. Marqués (1985, p. 19-28).

Hoje em dia o campo das Ciências da Educação concebe-se, de acordo com a ideologia, em três teorias ou paradigmas educativos que se denominaram paradigma comportamentalista ou racionalista/positivista (por vezes designado por tecnológico, que é comum a todos os paradigmas), paradigma interpretativo, naturalista, hermenêutico ou compreensivo e o paradigma (sócio) crítico ou transformativo (Quadro 1). Há um conjunto de diferenças entre estes três paradigmas teóricos (correspondente ao mundo 2 de POPPER) com implicação na educação.

Não vamos discutir a coerência ou a falta dela entre a teoria e a prática, tal como a coerência entre uma ideologia e a sua prática educativa (inserção no mundo 1 e 2 de POPPER), mas sim entre esta teoria e a prática ideológica e a teoria do caos ou da desordem e a indeterminação ou complexidade (relação entre o mundo 2 e 3 de POPPER). A investigação-acção, por exemplo, de corte (sócio) crítico introduz o aluno numa situação caótica, de desconhecimento, da qual tem que indagar e emergir informação (por exemplo, por meio da aprendizagem de labirinto). Ou seja, o conhecimento gera uma nova ordem (arquitectura do conhecimento no aluno), como podem ser, por exemplo, as aplicações etnográficas na aula.

Há teorias ideológicas que nunca conseguiram a coerência entre teoria e prática. O marxismo teve como objectivo fazer praxis da teoria e da teoria praxis, enquanto os marxismos descodificados não o conseguiram. Por outro lado, são também exemplos dessa harmonização de teoria e prática, P. Freire com a razão ideológica (a educação como prática da liberdade) ou A. Neill na coerência entre teoria anti-repressiva e anti-autoritária e a prática da liberdade e da anti-repressão. A pretensão de algumas destas teorias foi dar conhecimento acerca do tipo de conhecimento que corresponde à educação, sem definir os postulados em que se apoiam as práticas educativas específicas. O desconstruir uma teoria será a aurora que nos abre as portas para construir o

Educ. e Filos., Uberlândia, v. 21, n. 41, p. 89-120, jan./jun. 2007. 
conhecimento (nova ordem) (ADAMS \& RUSS, 1992, p. 196-199; BALAUDIER, 1996).

Efectivamente, a educação deve ser pensada e feita entre a acção e o pensamento, com elevados níveis de coerência. Por isso, toda a prática educativa tem como objectivo a construção do conhecimento dos alunos. Desta forma, fundamentamos uma teoria educativa (construção do conhecimento educativo) assente em bases complexas que nos ajudam a construir esse conhecimento no aluno. É óbvio que a construção do conhecimento e a realização da prática educativa devem obedecer a uma mesma proposta, ou seja, devem apoiar-se sobre idênticas bases, como única possibilidade para alcançar o encaixe entre a teoria e a prática. $\mathrm{Na}$ nossa perspectiva, um enfoque complexo do comportamento educativo exige uma determinada prática educativa que corresponda a uma teoria, de tal maneira que o pensamento e a acção e a prática sejam consequência de uma e/ou da outra. De facto, o conhecimento deve ser extraído da prática, e a prática deve ser fonte de conhecimento.

Pensamos que este seja um dos postulados epistemológicos em que se apoiam o conhecimento e a educação, de modo a descobrir a verdadeira realidade da educação. Realidade essa que nos é ou foi dada pelos professores, os ensaios e os manuais até agora. Por isso, esta realidade que enfrentamos não tem nada de sistemática, nem evidencia fundamentações imutáveis e carece de leis e de comparações o que não serve para os alunos. De facto, rompe a lógica evolutiva deles, pois surgem problemas e situações em que se dão processos e procedimentos ocultos que dificultam a eficácia da acção educativa.

Enfim, uma série de fenómenos que não são explicados pelas teorias sistematizadas apoiadas na ordem da 'modernidade, mas que acontecem nas salas de aula. De tal forma, que a realidade escolar é diferente da realidade teórica escolar e, por isso, podemos dizer que não construímos nenhuma teoria educativa pertinente. A complexidade actual permite-nos mostrar, tal como é, a realidade da educação: fenómeno irreversível no tempo, não linear, com diferenças significativas no seu ponto de partida (diversidade 
genética e social, biológica e psicológica, cultural e de turma), imprescindível, de alta contingência, continuamente estruturante. É lógico que, vendo a realidade educativa tal como ela é, se desconstruam as teorias e se construa o pensamento do aluno a partir da prática educativa.

Por conseguinte, a construção do conhecimento teóricoprático, no âmbito da educação, faz com que nos introduzamos no mundo 3 de POPPER. Por isso, o discurso deve ser coerente, abrangente e explicativo da fenomenologia que está presente em qualquer teoria particular de corte educativo (mundo 2 de POPPER). Isto é, qualquer prática ideológica da educação tem o seu correlato e vem explicada e abarcada pela epistemologia da complexidade. Por exemplo, a educação dialógica, os processos hermenêuticos ou as práticas da Pedagogia crítica têm os seus correlatos e explicações epistemológicas na teoria da complexidade. $\mathrm{Na}$ área das Ciências da Educação concebem-se, actualmente, de acordo com a ideologia, três paradigmas educativos, denominados paradigma condutista (ou paradigma tecnológico), paradigma interpretativo ou hermenêutico e paradigma sócio crítico. No Quadro 1 descrevemos as características básicas desses três paradigmas e as diferenças que se dão entre as três posições teóricas (mundo 2 de POPPER). São exemplos claros, por um lado, a investigação-acção, de corte crítico, que introduz o aluno em situações complexas, desconhecidas, desordenadas e incertas, da qual terá de surgir a informação, o conhecimento e, conseqüentemente, uma nova ordem. Por outro lado, nas aplicações etnológicas na sala de aula (paradigma hermenêutico), deparamos com uma metodologia que descobre as situações e as ordens complexas ou difíceis que se dão ao nível (des)organizativo que os alunos protagonizam por meio de seus grupos e, em geral, por meio de suas dinâmicas internas.

Houve teorias ideológicas que nunca alcançaram a coerência entre teoria e prática, como, por exemplo, o marxismo que teve com objectivo o fazer praxis da teoria, e da teoria, praxis, ainda que a realidade fosse o que os marxismos, em regimes políticos,

Educ. e Filos., Uberlândia, v. 21, n. 41, p. 89-120, jan./jun. 2007 
não alcançaram. Não foi o caso de P. Freire que soube articular uma razão (ideológica) que reúne a teoria e a prática: não pode haver educação como prática de liberdade se, simultaneamente, não se realiza uma pedagogia do oprimido. A opressão só é superável em contexto de liberdade. O caso de A. Neill na escola de Summerhill, como já referimos, é outro exemplo de coerência entre a teoria anti-autoritária e a prática da liberdade em autogoverno (autogestão), que se alcançavam a partir de aspectos organizativos e normativos desordenados (DOLL, 1989, p. 67).

Não há dúvida de que, no âmbito da construção do conhecimento, a complexidade e a desordem nos propõe um modelo crítico e reflexivo que abre novas formas de pensar a realidade e, paralelamente, de difícil adaptação a normativos legais. Esta epistemologia apresenta uma nova visão do mundo, da realidade e do conhecimento, que abre novas perspectivas, com uma carga (sócio) crítica (DAVIS \& SUMARA, 1997, p. 111114)

Insistimos na afirmação já formulada: Como da desconstrução de uma teoria da educação surge a construção do conhecimento educativo (desde o aluno)? Como este conhecimento tem aplicação na escola refundada e adaptada à sociedade do conhecimento? Estas questões tratam de demonstrar que a complexidade nas situações actuais de educação/formação serve de nexo entre a teoria e a prática e, simultaneamente, na confluência entre o pensar e o (saber) fazer (ELIARD, 2002). Esta é a possibilidade de construir o conhecimento para uma nova ordem da educação/formação e que deverá partir desde a cultura escolar e do projecto curricular de turma, constituindo-se a escola e os professores seus mediadores.

\section{O sentido da teoria da educação}

Entre as diversas ciências da educação encontramos a 'teoria da educação' que aborda o estudo teórico da prática (educação), afastando-se da origem grega e alemã (Pedagogia) que se aplicava ao conhecimento teórico (racional, sistemático, fundamental da 
educação). A 'teoria da educação' é uma das muitas ciências da educação que tem como objecto o estudo teórico da educação. ${ }^{3}$

De facto, a teoria da educação (anglo-saxónica), originada da fragmentação da Pedagogia (germânica), constitui um corpo específico de conhecimentos que integra uma constelação de saberes sobre a educação (ciências da educação), que o desenvolvimento científico e de investigação educacional propiciou e que tem como características:

- Uma concepção teórica que se aproxima do desenvolvimento das ciências humanas;

- Uma concepção da teoria como saber ou conhecimento aplicativo à realidade escolar e não escolar, cujos objectivos são a inovação e a mudança da prática educativa.

Efectivamente, é difícil definir o sentido da teoria da educação, já que pressupõe uma intenção unificadora. Se adoptamos a teoria da educação em vez de Pedagogia, integramo-nos na perspectiva anglo-saxónica dessa realidade científica, de âmbito educativo e pedagógico.

A área concreta do domínio da 'teoria da educação' (teoria para a prática) está constituída pelos contributos orientados a "conhecer a realidade educativa", com o objectivo de intervir (modificar, melhorar, inovar) sobre a realidade educativa (conhecer para melhorar a prática). O seu espaço formal é dado pelo conhecimento, o que implica melhoria da prática educativa, integrando a informação e o conhecimento proveniente das Ciências da Educação.

Sabemos que nem todo o conhecimento teórico da educação forma parte da teoria da educação, já que esta aborda dois campos educativos: o escolar (formal) e o não escolar (aprendizagens não formais). No primeiro, designa-se por teoria do currículo e, no segundo, pela educação não formal/informal.

3 E. KANT admitia uma concepção clássica da Pedagogia considerando-a 'teoria da educação'. Deste modo, a 'teoria da educação' seria uma disciplina surgida de uma vocação analítica das ciências da educação e, também, com uma visão de síntese, unitária e geral, da educação (perspectiva teórica).

Educ. e Filos., Uberlândia, v. 21, n. 41, p. 89-120, jan./jun. 2007 
Pela sua origem pragmática e utilitária, a teoria da educação (Escola de Chicago), contrapôs-se à corrente mais racional, fundamental, reflexiva e filosófica da Pedagogia alemã (área da filosofia da educação), que assenta no 'conhecer para fazer'. De facto, o conhecimento sobre a realidade educativa, propiciado pelas ciências da educação, por meio das diversas metodologias (descritivas, experimentais e analógicas), possibilita a esse conhecimento da realidade, formas de intervenção eficaz, com o intuito de melhorar ou modificar as situações educativas, como reafirma A. J. Colom (2001, p. 12-19).

Trata-se do 'saber para saber fazer', do 'conhecer para fazer' que encontra na educação formal, na educação não formal e na educação informal os seus campos de aplicação, com os respectivos desenvolvimentos (teoria do currículo, educação social, educação ambiental, educação cívica e para a cidadania, educação para o consumo, etc.).

A estrutura conceptual da teoria da educação concentra-se, pois em três níveis de conhecimento (COLOM, 2001):

- Nível meta-teórico: concepção da realidade (educação), do conhecimento dessa realidade educativa (epistemologia) e das formas para aceder a essa realidade (processos heurísticos e metodológicos);

- Nível teórico-científico: contributos das ciências da educação e de outras disciplinas que permitem conhecer a realidade educativa onde intervêm.

- Nível tecnológico de aplicação: educação formal (teoria curricular) afectando a prática educativa escolar, numa perspectiva científica e teórica; educação não formal (educação social, educação ambiental, educação intercultural); e educação informal.

Independentemente do sentido paradigmático, consideramos a teoria da educação como um âmbito teórico-tecnológico (teoria tecnológica). Contudo, não devemos confundir o processo 'tecnológico', 'crítico' ou 'hermenêutico' com o objectivo da teoria da educação em 'conhecer' (teoria) para 'fazer' (tecnologia), já que a tecnologia própria do 'fazer' (racional) requer essencialmente processos críticos (pedagogia de P. FREIRE), 
tecnológicos (ensino à distância, e-learning) e hermenêuticos (estratégias etnográficas).

$\mathrm{Na}$ verdade, a compreensão de toda a realidade educativa (teórica e prática) e de todas as posições epistemológicas daria uma 'epistemologia da teoria da educação' enquadrando-se esta num discurso próprio do mundo 3 de POPPER, enquanto a teoria da educação em si mesma, incide sobre as realidades educativas correspondentes ao mundo 2 de K. POPPER.

\section{O cenário da construção do conhecimento pedagógico}

Qualquer 'desconstrução' da teoria da educação implica a negação da teoria educativa apoiada sobre uma ordem imposta pela modernidade (sociedade pré-tecnológica e informativa). É neste contexto que construir o conhecimento ou o saber pedagógico seria referir-se aos seguintes dois aspectos:

-A construção do novo conhecimento da teoria da educação dada pela nova concepção do que a realidade e a sociedade do conhecimento nos oferecem e, ainda, pelas respectivas contribuições que confirmam a complexidade na actualidade. Neste sentido, desconstruir a teoria e construir o conhecimento seria sinónimo da necessidade de nos afastarmos das teorias educativas apoiadas na visão de ordem da modernidade, que já não têm a pertinência adequada, e iniciar a construção de uma teoria da educação adaptada à actualidade da ciência e da própria realidade complexa. Este processo de vaivém iria da des-construção da teoria à construção de um novo conhecimento pedagógico sobre a teoria da educação, nos actuais contextos educativos e sociais (DOLL, 1989).

-Uma nova teoria educativa não pode ser realizada como forma conceptual, fazendo adaptações teóricas aos novos enfoques, às questões educativas mais importantes pela teoria da educação. Este não é o caminho mais adequado, já que desde a prática pedagógica na escola construímos a teoria (conhecimento educativo) e, simultaneamente, construímos o conhecimento no aluno, na diversidade de aprendizagens (DAVIS \& SUMARA, 1997, p. 110-116). 
Como podemos epistemologicamente compreender este pressuposto?

Na nossa perspectiva, em primeiro lugar, haverá que ter bem presente qual é o espaço que a teoria da educação ocupa na complexa trama das ciências da educação e, em segundo momento, devemos saber que tipo de conhecimento queremos construir dentro delas.

No primeiro ponto é bem claro que a teoria da educação é uma das denominadas ciências da educação, que apresenta conhecimento sobre o que é a educação, servindo-se das outras ciências da educação, como por exemplo, da sociologia da educação, da psicologia da educação, da economia da educação, da antropologia da educação, etc. Assim, o sentido da teoria da educação será dado pelas diversas ciências humanas, desde a abordagem que fazem à educação. Esta questão leva-nos à análise diferencial entre ciência e tecnologia. Se a teoria da educação pretende tratar o conhecimento sobre a educação, este conhecimento deverá incidir na forma de levar a educação à prática, pois a educação só tem sentido como acção na prática (HARGREAVES, 1995, p. 219-221).

No contexto desta argumentação, a teoria da educação não analisa teoricamente a educação, mas sim fundamenta-se em teorias das diversas ciências humanas aplicadas à educação, para melhorar a prática educativa. O saber para fazer é o que define verdadeiramente a teoria da educação e a distingue da filosofia da educação, que estuda a educação de forma ontológica, como fenómeno - objecto de conhecimento, com independência de sua colocação na prática. Por isso, todo o conhecimento teórico sobre a educação sem aplicação prática (não se procura esse objectivo) faz parte, de uma forma ou de outra, da filosofia da educação, já que a educação pode ser pensada e, por isso, pode ser considerada como objecto de análise e reflexão ontológica (BREZINKA, 1990).

Por conseguinte, a teoria da educação é teoria não porque o seu objecto de conhecimento seja teórico, mas sim porque se utiliza para melhorar a prática educativa (fazer), pois, desde uma perspectiva realista e pragmática, conhecer a educação é conhecer 
a sua prática, as formas de aplicação e as acções que nos conduzem à apreensão dos objectivos conseguidos por meio da prática. $\mathrm{Na}$ teoria da educação, conhece-se as teorias para aplicar projectos ou planos de educação e, desta maneira, ela é-nos apresentada como uma forma de conhecimento teórico - tecnológico (dimensão tecnológica da educação).

Trata-se de uma forma de 'conhecer para fazer' que, epistemologicamente, se designa por racionalidade tecnológica, que não conforma um paradigma determinado, mas que é uma constante comum a qualquer visão teórica que façamos da educação nos seus contextos. Por isso, a racionalidade tecnológica pode ser comum a qualquer teoria ou visão específica da educação. Dissemos, que no paradigma condutista, é necessário o conhecimento prévio de práticas educativas determinadas para alcançar os seus objectivos, tal como acontece no seio dos paradigmas hermenêutico e crítico (Quadro 1). Por exemplo, se um professor quer desenvolver práticas etnográficas na sala de aula, terá que conhecer e ter informação prévia da etnologia aplicada à educação (HALSALL \& COCKETT, 1996, p. 30-39).

Portanto, em educação, e sob qualquer paradigma ou teoria compreensiva do que é a educação, teremos que saber para fazer, fazendo. Esta é, quanto a nós, a característica comum a qualquer proposta doutrinal que se tenha sobre a educação, centrada no "saber fazer" ou no "conhecer para aplicar". A isto denominamos racionalidade tecnológica, que é necessária em qualquer caso particular do saber educativo (COLOM, 2001).

De facto, o tecnológico na educação não corresponde a uma forma de entender a educação, mas sim à caracterização do saber correspondendo a qualquer fenómeno ou realidade educativa. Em educação, toda a teoria, seja ela libertadora, anarquista, crítica, anti-autoritária, por objectivos ou por procedimentos, é sempre uma teoria de carácter tecnológico, pois toda a prática educativa se dilui em conhecimentos aplicáveis. Ou seja, a racionalidade tecnológica é uma constante em qualquer ideologia educativa que esteja orientada à prática.

Educ. e Filos., Uberlândia, v. 21, n. 41, p. 89-120, jan./jun. 2007 
Efectivamente, se essa é a concepção epistemológica da teoria da educação, não há dúvidas de que a nova construção que essa teoria educativa exige é a de ser prática. Este novo caminho de construção do conhecimento teórico implica o sentido que deve ter a teoria para a prática educativa, nos contextos diversificados de aprendizagens na realidade educativa actual. De facto, a construção do conhecimento teórico-educativo deve iniciar-se pela construção do conhecimento da prática educativa, que é o mesmo que dizer: construir o conhecimento no aluno (arquitectura do conhecimento). É nessa possibilidade epistemológica que defendemos uma teoria da educação que se construa a partir da acção, em que o objecto dessas acções educativas são as crianças, os alunos ou os educandos, a aprendizagem ao longo da vida (modelo de aprender a aprender). Portanto, não pode existir teoria educativa sem possuir prática educativa, e sem esta não ocorre a primeira (coerência epistemológica).

Construir, pois o conhecimento da teoria da educação determina processar formas de construção do conhecimento do aluno. Mas, só é possível construir esse conhecimento do aluno de forma complexa, se falarmos da construção de uma teoria complexa da educação, isto é, uma teoria que integre a visão que as ciências têm da realidade, desde a biologia ou da psicologia à sociologia. $\mathrm{O}$ pensamento 'fundacional' seria de novo (re)estabelecido como consequência do estabelecimento de uma realidade escolar refundada (GIROUX, 1981).

A teoria da educação deve ser consciente de que algo mudou na sociedade educativa actual e, até, nas formas de vida e no modo de narrar a própria vida. Haverá, pois, que resgatar as acções educativas já conhecidas com novas implicações na realidade educativa, a fim de alcançar, na prática, uma educação adequada às mudanças, à inovação e à nova sociedade do conhecimento. Desta forma, possibilitamos alguns caminhos que fazem com que construamos o conhecimento do aluno sob as mesmas propostas em que elaboramos a teoria educativa. 


\section{Novas práticas educativas}

Defendemos uma prática educativa para uma educação transformadora, adaptada às condições sociais em que se deve desenvolver a educação na sociedade actual (rede).

Em seguida, descreveremos algumas dessas possibilidades educativas ao nível da prática pedagógica. Não trataremos de desenvolver um repertório de métodos e de práticas conhecidas, mas orientações para iniciar uma educação a partir da situação de complexidade, que é o cenário actual. Indicaremos algumas experiências que podem (re)conduzir o sentido da aprendizagem no aluno ou educando, sem tratar de fixar uma série de práticas de diversas origens e para situações diversificadas, apesar de todas elas serem aptas para serem aplicadas, na perspectiva do paradigma sociocognitivo humanístico e axiológico.

Aprendizagem em modelo de labirinto (pedagogia do desejo; método de indagação e de resolução de problemas). Esta proposta de aprendizagem em labirinto introduz o aluno em situações complexas, indefinidas ou confusas, que não conhece. $O$ professor motiva e conduz o (s) aluno (s) a uma situação de aprendizagem não estruturada (planificada), de tal maneira que este com o esforço, poder de iniciativa e capacidade de indagação, procura (individual e/ou em pequenos grupos), com a ajuda de meios educativas ou materiais, esclarecer e resolver as questões propostas. $\mathrm{O}$ modelo de aprender em forma de labirinto seria a procura de sentido (guia, significação) do que faz. Daí a importância que contêm essas situações de aprendizagem, os exercícios hermenêuticos e o exercício da memória (o aluno recorda o que vai fazendo progressivamente), que é uma forma de registo de experiências ou de vivências.

Os alunos neste tipo de aprendizagem em labirinto partem de situações complexas e/ou ideias perturbadoras e desafiadoras, de modo que por meio da indagação, da motivação da resolução de problemas (aprender por descoberta) ou de exercícios ou experiências, possam estabelecer explicações às questões geradas ou propostas. Este modo de aprender pode utilizar as novas tecnologias, já que estas são instrumentos úteis na aprendizagem.

Educ. e Filos., Uberlândia, v. 21, n. 41, p. 89-120, jan./jun. 2007 
Cremos que o aluno não deve aprender conteúdos culturais já manifestados e sistematizados, mas sim deve reconstruir a cultura (global, social e institucional), o que significa que o professor deve apresentar sempre situações complexas, que não sejam de mera análise, sistematizadas, de evidências e de linearidades. Com isso, se desconstrói a cultura escolar, fugindo das simplificações da paideia. Caberá ao aluno manifestar a sua individualidade, os seus desejos, iniciando a construção de uma cultura escolar. Deste modo, o processo de aprender deve basear-se, como dizia Coménio, no labirinto do mundo e na paixão do coração (prazer) (COLOM, 2001).

A moralidade na escola só poderá chegar por meio do desejo e os alunos devem procurá-la, construindo a moral do desejo ou da emancipação e autoconstrução. A verdadeira construção da moral segue os mesmos caminhos de construção cognitiva, num desejo de desenvolvimento auto-construtivo (memória construtiva). A informação e formação, a aprendizagem e moralização seguem caminhos paralelos que, a partir da desordem e do prazer ou do desejo, conduzem à criação do conhecimento e do próprio 'EU'. No labirinto não servem os velhos esquemas construídos, mas sim a situação de desconstrução e a aposta em novas soluções. O aluno pode construir a saída, indagando e conhecendo.

Aprendizagem interpretativa (tomar decisões). $\mathrm{O}(\mathrm{s})$ modelo(s) de aprendizagem complexo devem incidir numa transformação do currículo e da formação de professores (inicial e contínua). $\mathrm{O}$ aluno interpreta o que deve aprender a partir de um grande número de possibilidades, de leituras, de actividades, de exercícios, de pesquisa, etc., que lhe são apresentados sem uma ordem preestabelecida. Cabe-lhe a ele seleccionar a informação e construir o seu próprio conhecimento, de acordo com os objectivos que lhe tenham sido estabelecidos. Neste sentido, o processo de aprendizagem é um processo paralelo ao de sair do labirinto, de tal maneira que o aluno realiza o seu itinerário, e vai aprendendo o caminho que o conduz para a saída, para os objectivos desejados (capacidades). A sua aprendizagem processa-se por meio da desconstrução do conhecimento e da cultura, de modo que seja o

Educ. e Filos., Uberlândia, v. 21, n. 41, p. 89-120, jan./jun. 2007. 
aluno quem adquira uma ordem no seu processo de formação, ou seja, uma nova plataforma de conhecer e aprender.

Na história da educação temos um precedente entre a teoria interpretativa e a teoria do desejo, própria do labirinto (desejo de sair), que foi a do pedagogo soviético Vasil Sujomlinski (1918-1970), criador da 'escola da alegria' (COLOM, 2000, p. 42-47). Esta escola, estruturada em graus, propunha uma prática educativa naturalista propícia ao desenvolvimento da individualidade da criança dentro do grupo. Os 'campos de tensão', assim designados por Sujomlinski, consistiam na necessidade de realizar, por meio da actividade quotidiana escolar, o mais difícil para a criança ou aluno.

A escola deve facilitar a aprendizagem por meio da análise, das explicações, das orientações, da pesquisa voluntária, do estudo autónomo, do desenvolvendo de actividades escolares com diversos níveis de dificuldade, considerando aqui o 'difícil' como forma de motivação para o aluno, isto é, o 'desejo' de superação, que o leva a 'fazer'. A promoção de tensão interessada nos alunos na sala de aula (clima de tensões), obriga-os a superar por si mesmos as dificuldades, já que estas motivam mais que as tarefas fáceis. Cremos que a complexidade das actividades escolares, em determinados níveis de ensino, trazem consigo níveis de sucesso nos alunos. Aquele exemplo de prática educativa de Sujomlinski incita a actividade escolar a partir da complexidade e da dificuldade, por isso, se assemelha à teoria da aprendizagem e do nível pulsional que vai despertando no aluno o desejo (sentido em MONTESSORI) de construção da própria aprendizagem (COLOM, 2001, p. 21-23).

$>$ Autogestão educativa. Trata-se de desenvolver situações de autogestão, propostas pela pedagogia institucional e por modos anárquico-educativos de entender a educação. Por exemplo, nas Casas do Gaiato do Padre Américo em Portugal, os rapazes estabelecem a sua própria ordem, sem a ajuda ou a intervenção dos educadores (MARTINS, 2004). Ao nível escolar o professor não normaliza o grupo na sala de aula, não impõe um horário, nem um programa, nem um projecto de convivência. A turma ou o grupo parecem desorganizados, desordenados, sem estruturação

Educ. e Filos., Uberlândia, v. 21, n. 41, p. 89-120, jan./jun. 2007 
de nenhum tipo, mas cabe aos educandos reestruturar-se e ordenarse em função dos seus desejos (mesmo em autogoverno). São os alunos que protagonizam a solução para a desordem estabelecida, criando as suas próprias normas ou, como afirmam os pedagogos institucionalistas, gerando as próprias instituições ou normativas de funcionamento instituído pelo próprio grupo (COLOM, 2000).

No seio da autogestão escolar os alunos iniciam o seu processo de aprendizagem em função de seus interesses (desejo de novo), o que implica o desconstruir da moralidade preestabelecida, em nome da liberdade ou da autonomia, que pode ser um patamar de realização de projectos educativos, aceite por todos. A ordem estabelecida irá variando à medida que forem surgindo novas formas de auto-organização. Na dinâmica da sala de aula há um sucessivo aparecimento de ordens e desordens que vão determinar os desejos dos alunos, assim como toda sua actividade curricular. A pedagogia institucional, no âmbito organizativo da sala de aula, é um bom exemplo de aplicação para determinados tipos de aprendizagem dos alunos.

Investigação-acção. As actividades de pesquisa, provenientes da pedagogia de J. Dewey e da pedagogia crítica, dão um papel preponderante aos alunos (indagação, resolução de problemas, pesquisa) o que pressupõe uma mudança na situação de normatividade da aprendizagem na sala de aula e do grau de dificuldade que normalmente se dá nas actividades escolares. As práticas destes modelos escolares implicam uma ruptura com a ordem estabelecida na aula, promovendo motivações e iniciativas de pesquisa, que envolvem o desejo e a motivação/vontade dos alunos, levando-os a realizar tarefas e actividades difíceis ou complexas.

Reiteremos que para os alunos a 'investigação-acção' ou simplesmente a 'pesquisa' constitui uma ruptura da rotina e da ordem escolar que proporciona o início de um processo incerto (no processo, nos procedimentos e do final) que se manifesta em função das necessidades do projecto (etapas). Não se trata de relatar os princípios em que se apoia a pesquisa, mas a possibilidade pedagógica de promover caminhos de indagação, do desconhecido, 
de reflexão e acção, como, por exemplo, no método de projecto de Kilpatrick, que, entendido ao nível da aprendizagem, permite construir o conhecimento do aluno.

$>$ Educação ambiental. Este tipo de educação apresenta uma perspectiva prática adequada à complexidade das situações de aprendizagem, aos problemas entrelaçados em ecossistemas, o que obriga ao aluno a pensar em termos de complexidade. De facto, a educação ambiental ensina uma visão sistémica da realidade educativa referente a elementos de inter-relação, apreciando os alunos os problemas ecológicos e ambientais, de modo a praticar um pensamento complexo sobre o 'meio-ambiente'. Na escola a liberdade dos alunos deve ser vista como uma situação de desordem ou de preocupação, que deve ser controlada pelo professor. É essa liberdade dos alunos que permitirá construir as suas próprias práticas educativas congruentes com os fundamentos das situações ou tarefas.

$>$ Criatividade e originalidade (aprendizagem criativa). Para haver uma coerência entre a teoria e a prática da educação depreendemos a necessidade de um desenvolvimento da criatividade, considerando a criatividade como o lado errático da razão e a qualidade da inteligência humana (divergência). $\mathrm{O}$ aluno criativo é aquele que tem originalidade, que diante de uma situaçãoproblema manifesta características próprias (emergentes), originais e espontâneas (criação de novos saberes e conhecimentos).

Por conseguinte, o acto criativo implica distanciação da sequência de normas para alcançar um pensamento divergente, que foge à normalidade. O produto da criatividade é algo improvável, o que foge do normal, do desconhecido ou do sabido. Na escola a criatividade dos alunos pressupõe mudança, desordem, improbabilidade, o que perturba a ordem lógica estabelecida na aula para propor um novo formato de análise ou de realização.

Os alunos muitas vezes expressam uma imaginação criativa que é vista pelo adulto como fuga da realidade (pensamento simbólico). Na escola, o desenvolvimento da sociabilidade e da leitura, o contacto com os iguais e com a realidade faz com que os alunos sejam receptores de imagens ou representações concretas

Educ. e Filos., Uberlândia, v. 21, n. 41, p. 89-120, jan./jun. 2007 
(exercícios de memória). Sabemos que é na adolescência que se dá o verdadeiro pensamento criativo (como exemplo, as filosofias juvenis evidenciadas por J. Piaget) ou propostas ontológicas e pessoais sobre a realidade (exercícios criativos e imaginativos em todos os âmbitos culturais).

Em geral, os alunos criativos no sistema educativo são tratados como fracassados, já que na escola se premeia a inteligência convergente ou de integração normativa. Estamos habituados a ver como inteligente o aluno que faz bem e rapidamente os exercícios propostos pelo professor o que obedece às suas normas, se adapta às suas exigências e que converge com os outros seus colegas. O aluno original e criativo transforma-se, muitas vezes, num problema para os professores (disciplina, baixo rendimento escolar), constituindo-se num aluno aborrecido, fazendo contrariado o que lhe mandam, com comportamentos fora das normas, pois o seu pensamento e a sua forma de ver a realidade é divergente daquilo que o sistema educativo e a escola esperam dele. Neste sentido, a escola nega ao aluno as oportunidades de demonstrar as suas capacidades criativas, e até reprime e castiga os comportamentos que se afastam das normas impostas, como afirmam BRIGGS e PEAT (1994).

A nova epistemologia da educação exige uma mudança escolar, apostando numa escola que desenvolva e possibilite a criatividade, a imaginação, a originalidade e a espontaneidade dos alunos. Deve ser uma escola que eduque para uma sociedade em mudança e contingente, para a adaptação contínua a novas propostas e perspectivas, formando nesse sentido os futuros cidadãos. Daí que a criatividade signifique mudar e implementar novas ordens que podem ser superadas por acções criativas (GIROUX, 1981).

A psicopedagogia do desenvolvimento criativo permite ao professor fazer com que a escola se adapte às novas exigências sociais e educativas da sociedade. J. Dewey e O. Decroly falavam de educar para a vida, de uma educação pragmática e vivida. É nessa perspectiva que se deverá integrar a escola de educar para a mudança, para a vida e para a contingência. Neste contexto, a 
criatividade integra essa situação e readaptação constante às mudanças.

> Hipertexto. A utilização hipertextual na escola não é um método único, mas um elemento auxiliar para o desenvolvimento de actividades escolares no contexto de aprendizagem, da construção de uma prática complexa de educação. Somos conscientes das aplicações do hipertexto na comunidade escolar, pois constitui um meio auxiliar ao serviço dos alunos na procura de informação. Tem uma funcionalidade cognitiva. Os alunos em contextos desordenados tendem a alcançar uma nova ordem, por isso o hipertexto permite níveis de auto-regulação, de motivação, autodomínio e de desenvolvimento de habilidades metacognitivas nos alunos (por exemplo, a habilidade leitora).

A validade do hipertexto verifica-se como prática em questões ou contextos complexos de forma sistémica, como são as experiências de S. Spielberg (Fundação Shoa), com o uso dos multimédia e outros meios tecnológicos ou audiovisuais. Neste sentido se integra uma educação de valores (tolerância, solidariedade e respeito), mesmo em situações de multiculturalidade (DAVIS \& SUMARA, 1997, p. 108-112; FOERSTER, 1996, p. 4348).

O aluno elabora a sua teoria, constrói o seu conhecimento a partir de situações complexas, da desconstrução com a qual se apresenta a complexidade hipertextual. Deste modo, converte-se em protagonista do seu próprio desenvolvimento, em que a aprendizagem em situações complexas lhe propicia a construção do conhecimento (elaboração teórica). A estratégia, no fundo, do trabalho do aluno diante dessas situações complexas, próprias do hipertexto, é a de obrigá-lo a desenvolver uma tarefa hermenêutica de esclarecimento e de dar sentido à sua própria actividade escolar (conteúdos de aprendizagem) (TORRES, 2006).

Em suma, na escola o desenvolvimento e a potencialidade da criatividade, a hipertextualidade, entendidas como estratégias educativas, requerem liberdade de produção e de troca comunicativa, aumentando a selecção, a sequência, a síntese e a

Educ. e Filos., Uberlândia, v. 21, n. 41, p. 89-120, jan./jun. 2007 
retenção da informação aprendida nos alunos. O hipertexto permite uma pluralidade de caminhos ou possibilidade, nenhum deles impostos por nenhuma norma ou regra de inferência, e promovendo resultados que nem sempre são os mesmos. Na prática educativa de sala de aula o sistema hipertextual facilita a aprendizagem, um uso eficiente dos meios, uma fácil lembrança, ao retomar a aprendizagem motivadora de fácil acesso (SCHELEICHER, 2005). De facto, o hipertexto e a criatividade, unidos à aprendizagem orientada para a resolução de problemas, incidem num tipo de aprendizagem de labirinto, em que se exige ao aluno a construção do seu próprio conhecimento com base nas relações e na utilização de esquemas mentais próprios de um pensamento sistémico e complexo.

\section{(IN) Conclusões: perspectivas pedagógicas de futuro}

Abordamos nos pontos anteriores alguns aspectos referentes à construção de uma nova forma de aprendizagem, que deve ser construída pelos alunos na escola desde contextos ou situações complexas. Neste sentido, requer-se desconstruir a escola da(s) teoria(s), para depois se construir uma escola refundada, de acordo com o actual conhecimento que temos da natureza da sociedade da informação e do conhecimento.

Apostamos numa escola que não se apoie na linearidade e na análise, mas sim na complexidade e na síntese (pensamento sintético e sistémico). Uma escola aberta para a sua comunidade social e preparada para as mudanças, para a inovação e o desenvolvimento. Esta nova epistemologia implica uma nova teoria da educação que dê coerência à realidade educativa e à forma de conhecê-la. Efectivamente, as formas de aprendizagem proporcionam situações em que os alunos extraem da desordem as novas ordens que lhes servem como plataforma para iniciar outras actividades ou tarefas criativas e construtivas de conhecimento. A utilização do hipertexto, da rede, possibilita a adaptação à escola à actual realidade, ao mesmo tempo que se 
abrem novas perspectivas educativas para um futuro imediato. ${ }^{4}$

Dissemos que a criatividade evidencia a possibilidade de uma prática de conhecimento no aluno, ao mesmo tempo que afirmámos ser necessário a construção de uma teoria com o seu correlato na prática da sala de aula, do sentido do saber sobre a educação. Ou seja, é o saber educativo que tem aplicação na prática, encontrando a sua localização na razão tecnológica (dimensão tecnológica da educação).

Os alunos criativos são abertos, curiosos, integradores, toleram as tensões e sentem-se bem em ambientes indefinidos, sentindo-se, no entanto, frustrados ou inadaptados em ambientes normatizados e ordenados (sala de aula). São sujeitos de grande capacidade de síntese, unificadores de conceitos, parecendo que a divergência do seu pensamento se origina a dar coerência a elementos contrários. Daí lhes surge a originalidade, a improbabilidade e, por isso, há necessidade de uma educação multi-estimulante e multivariada em situações de aprendizagem (MAcPHERSON, 1995, p. 271-273; ROSNAY, 1996, p. 33-37).

Sabemos que o uso das novas tecnologias nas aprendizagens dos alunos implica novas perspectivas cognitivas, já que o uso do computador gera uma inteligência artificial, ao desenvolver no sujeito esforço e funcionalidades mentais sobre um mecanismo não natural. Frente a estas novas situações, o ser humano ensaia novas soluções, em que o computador e as situações de interacção o obrigam a produzir novas estratégias (cognitivas) e novas perspectivas na utilização dos recursos mentais. Este tipo de aprendizagem instrumentalizada e tecnológica reconverte essa

4 Algumas possibilidades educativas são confirmados pela neurofisiologia que nos permite conhecer as capacidades mentais do hemisfério direito, apesar de se opor ao desenvolvimento intelectual na escola actual, que se centraliza no desenvolvimento dos possibilismos do hemisfério esquerdo (na linguagem, nas sequências lineares, na capacidade de análise e na discriminação, etc.). $O$ ser humano possui outras capacidades que a escola secundariza dos seus interesses e objectivos (imagens, capacidade de síntese, visões globais, simultaneidade, conexões complexas, etc.), que se integram no que designamos por 'pensamento sistémico'.

Educ. e Filos., Uberlândia, v. 21, n. 41, p. 89-120, jan./jun. 2007 
tecnologia num meio facilitador dessas novas perspectivas cognitivas, em que a educação tende a converter-se numa tecnologia cognitivista, isto é, numa tecnologia própria da construção humana (TORRES, 2006; VATTIMO, 1990).

A compreensão do mundo hipercomplexo, não linear, em mudanças constantes, é bem evidente no uso hipertextual que a rede possibilita. Sendo a função da escola promover a construção de novas metáforas (e linguagens) e formas explicativas da realidade, deparamo-nos com uma adequação da realidade educativa à nova epistemologia estabelecida, desde a necessidade de uma nova escola e de uma nova educação (e de uma nova teoria da educação) para ensinar a ver o mundo de outra forma aos alunos, futuros cidadãos.

$\mathrm{O}$ 'possibilismo globalizador' e descentralizador na actual sociedade é capaz de ser compatível a partir do critério de identidade, isto é, pelo processo mediante o qual um actor social se reconhece a si mesmo e constrói o seu significado (relações). A sociedade global exige conjugar a paixão e a razão a que Coménio se referia na sua Didáctica Magna, ou seja, compatibilizar a globalidade que nos dá a rede, o labirinto, com a identidade do 'EU'. Acreditamos que é a escola que se deve preocupar em dar identidade pessoal e cultural e, por isso, deve conjugar a sua tradicional tarefa num contexto que agora é globalizado. Uma escola hipertextual e criativa transforma-se numa estrutura social baseada em redes, gerando, assim, um sistema dinâmico e aberto, susceptível à inovação (CASTELLS, 1999; TOFFLER, 1990).

Hoje em dia não compreendemos as dificuldades da escola em adaptar-se às novas coordenadas das novas tecnologias e multimédia e à compreensão complexa do mundo. Haverá, pois que criar um ambiente escolar em que os alunos saibam superar e empreender tarefas difíceis (desafios) e actualizem as suas potencialidades criativas e os seus desejos.

Provavelmente, a escola deve recuperar o tempo perdido, já que a Internet, as novas tecnologias ou a nova visão do mundo, além de serem evidências empíricas e desenvolvidas ao nível da ciência, não constituem agressão ao sistema educativo, pelo 
contrário, trazem novas características de interesse para a escola. Abrem-se, assim, novas fontes de informação e, simultaneamente, novas formas e instrumentos de aprendizagem (modelos), que abrem espaço e tempo na sala de aula, rompem a organização escolar (horários) e criam espaços de convivência, associação e reflexão (Projecto Curricular de Turma). Daí que as novas tecnologias poderem ser utilizadas na aprendizagem colectiva e nas novas formas de aprender, como vimos, com as novas concepções da realidade educativa e da ciência.

Por tudo o que ficou dito, acreditamos que o futuro está no equilíbrio entre a escola virtual e a escola real, porque a complexidade é, por sua vez, virtual e real, isto é, o uso das novas tecnologias torna-se necessário. Por este motivo a escola deve ter formas complementares e cultura e de acesso aos saberes, ao conhecimento, sendo possível compatibilizar a rede com o sistema educativo e, paralelamente, ser compatível uma escola com a biblioteca virtual. O que acontecerá é que a hipertextualidade, própria da rede, possibilitará formas complexas de aprendizagem e, ao mesmo tempo, a escola se preparará para a realidade da sociedade tecnológica, para as mudanças e para a reestruturação constante.

Em definitivo, a escola e os níveis de ensino podem democratizar as tecnologias e os multimédia para o bem dos seus objectivos educativos, porque o 'modelo de aprender a aprender' é também saber utilizar as novas tecnologias (competências, destrezas) e, por isso mesmo, a escola com a sua cultura escolar será a escola do desenvolvimento, da inovação e das tecnologias.

\section{Referências}

ADAMS, H. M. \& RUSS, J. C. Chaos in the classroom: exposing giffed elementary school children to chaos and fractals. Journal of Science Education and Technology, v. 1, n. 3, p. 191-209, 1992.

BALANDIER, G. El desorden y la teoría del caos y las ciencias sociales. Barcelona: Gedisa, 1996.

Educ. e Filos., Uberlândia, v. 21, n. 41, p. 89-120, jan./jun. 2007 
BREZINKA, W. La educación en una sociedad en crisis. Madrid: Narcea, 1990.

BRIGGS, J. \& PEAT, F. D. Espejo y reflejo: del caos al orden. Barcelona: Gedisa, 1994.

CASTELLS, M. La era de la información I: la sociedad red. Madrid: Alianza, 1999.

CASTILlEJO, J. L. \& COLOM, A. J. Pedagogía Sistémica. Barcelona: CEAC, 1987.

COLOM, A. J. Teoría y metateoria de la educación. Un enfoque a la luz de la teoría general de sistemas. México: Trillas, 1986.

COLOM, A. J. La Pedagogía Institucional. Madrid: Síntesis, 2000.

COLOM, A. J. Teoría del caos y educación (Acerca de la reconceptualización del saber educativo). Revista Española de Pedagogia, Año LIX, n. 218, p. 5-24, Enero/Abril. 2001.

COMÉNIO, J. A. Didacta magna: tratado da arte universal de ensinar tudo a todos. Tradução e notas de Joaquim Ferreira Gomes. 3. ed. Lisboa: Fundação Calouste Gulbenkian, 1985.

DAVIS, S. \& SUMARA, A. J. Cognition, complexity and teacher education. Harvard Educational Rewiew, v. 67, n. 1, p. 105-125, 1997.

DERRIDA, J. Psyché. Inventions de l'autre. Paris: Galilée, 1987, p. 11-22.

DERRIDA, J. Papier Machine. Paris: Galilée, 2001.

DOLL, W. E. Complexity in the classroom. Educational Leadership, v. 7, n. 1, p. 65-70, Sept. 1989.

DOMENACH, J-M. Abordagem à modernidade. Lisboa: Instituto Piaget, 1995.

Educ. e Filos., Uberlândia, v. 21, n. 41, p. 89-120, jan./jun. 2007. 
ELIARD, M. El fin de la escuela. Madrid: Grupo Unisión Edicciones, 2002.

FOERSTER, H. V. Las semillas de la cibernética. Barcelona: Gedisa, 1996.

GIROUX, H. Ideology, culture and process of schooling. London: The Falmer Press, 1981.

HALSALL, R. \& COCKETT, M. Education and training 14-19. Chaos in the classroom? London: David Fulton, 1996.

HARGREAVES, D. H. Self-managing schools and development planning. Chaos or control? School Organization, v. IV, n. 1, p. 215227, Oct. 1995.

HARGREAVES, A. (Coord.). Replantear el cambio educativo. Buenos Aires: Amorrortu, 2003.

HUNTER, W. J. \& BENSON, G. D. Arrows in time: the misapplication of chaos theory to education. Curriculum Studies, v. XXIX, n. 1, p. 87-100, 1997.

JONES, R. Chaos theory. The Executive Educator, v. 16, n. 10, p. 2033, Oct. 1994.

MACPHERSON, E. Chaos in the curriculum. Curriculum Studies, v. XXVII, n. 3, p. 263-279, 1995.

MARTINS, Ernesto C. O Projecto educativo do Padre Américo. O ambiente na educação do rapaz. Lisboa: Temas \& Debates; Círculo de Leitores, 2004.

MOLES, H. Les sciences de l'imprecis. Paris: Seuil, 1995.

MORIN, E. El método. La vida de la vida. Madrid: Cátedra, 1983.

Educ. e Filos., Uberlândia, v. 21, n. 41, p. 89-120, jan./jun. 2007. 
LIPOVETSKY, G. A era do vazio. Ensaio sobre o individualismo contemporâneo. Lisboa: Relógio D’Água Editores, 1989.

PIAGET, J. Seis Estudos de Psicologia. Tradução de Nina C. Pereira. Lisboa: Publicações Dom Quixote, 1977.

ROSNAY, J. El hombre simbiótico. Madrid: Cátedra, 1996.

SARRAMONA, J. \& MARQUÉS, S. Qué es la Pedagogia? Una respuesta actual. Barcelona: CEAC, 1985.

SCHELEICHERS, A. La mejora de la calidad y de la equidad en la educación. Madrid: Fundación Santillana, 2005.

TOFFLER, A. El 'schoc' del futuro. Barcelona: Plaza y Janés, 1990.

TORRES, J. La demotivación del profesorado. Madrid: Morata, 2006.

VATTIMO, G. La sociedad transparente. Barcelona: Paidós, 1990. 
Quadro 1. Características entre os paradigmas comportamentalista/condutista ou behaviorista, paradigma hermenêutico e paradigma crítico

\begin{tabular}{|c|c|c|c|}
\hline & \begin{tabular}{|l} 
Paradigma \\
comportamentalista
\end{tabular} & $\begin{array}{l}\text { Paradigma } \\
\text { hermenêutico }\end{array}$ & $\begin{array}{l}\text { Paradigma } \\
\text { crítico }\end{array}$ \\
\hline Professor & $\begin{array}{l}\text { Programador de } \\
\text { materiais e } \\
\text { experiências; } \\
\text { Estrutura da relação; } \\
\text { Relação com os outros; } \\
\text { Ensino } \\
\text { individualizado }\end{array}$ & $\begin{array}{l}\text { Organizador informal; } \\
\text { Individualização; } \\
\text { Assume o papel de } \\
\text { líder; } \\
\text { Relação pessoal; } \\
\text { Importância da } \\
\text { comunidade; } \\
\text { Procura a compreensão }\end{array}$ & $\begin{array}{l}\text { Actor implicado; } \\
\text { Conhecedor da realidade; } \\
\text { Orientado à comunicação; } \\
\text { Implicação nos processos; } \\
\text { Procura o desenvolvimento } \\
\text { pessoal }\end{array}$ \\
\hline $\begin{array}{l}\text { Desenvolvimento } \\
\text { Curricular }\end{array}$ & $\begin{array}{l}\text { Racionalização; } \\
\text { Organização } \\
\text { estrutural, funções e } \\
\text { papeis formais; } \\
\text { A aprendizagem como } \\
\text { base da formação }\end{array}$ & $\begin{array}{l}\text { Integrador; } \\
\text { Flexível; } \\
\text { Definição informal de } \\
\text { papéis e funções. } \\
\text { Fundamenta-se nos } \\
\text { interesses }\end{array}$ & $\begin{array}{l}\text { Negociação entre os } \\
\text { elementos intervenientes; } \\
\text { Diálogo com a realidade; } \\
\text { Transformador. Procura } \\
\text { emancipação e a libertação }\end{array}$ \\
\hline Investigação & $\begin{array}{l}\text { Ciência social como } \\
\text { réplica às ciências } \\
\text { naturais; } \\
\text { Objectividade; } \\
\text { Descritivo e } \\
\text { explicativo; } \\
\text { Obtém normas }\end{array}$ & $\begin{array}{l}\text { Intencional, governada } \\
\text { por regras/normas; } \\
\text { Interpretativo, } \\
\text { contextual. Procura } \\
\text { conhecimentos não } \\
\text { prescritivos }\end{array}$ & $\begin{array}{l}\text { Participativa, sócio-crítica, } \\
\text { integrada em contextos } \\
\text { ideológicos. Desde a prática } \\
\text { e orientado à acção. }\end{array}$ \\
\hline $\begin{array}{l}\text { Fenómeno } \\
\text { educativo }\end{array}$ & $\begin{array}{l}\text { Objectivo e } \\
\text { mensurável; } \\
\text { Actividade racional } \\
\text { pré-programada; } \\
\text { Organização regulada }\end{array}$ & $\begin{array}{l}\text { Subjectivo; Importância } \\
\text { do contexto; } \\
\text { Vital, pessoal e cultural; } \\
\text { Variabilidade e } \\
\text { interactivo }\end{array}$ & $\begin{array}{l}\text { Interpretado desde as } \\
\text { condições históricas e } \\
\text { culturais. Participativo, } \\
\text { crítico e construtivo }\end{array}$ \\
\hline Teoria & $\begin{array}{l}\text { Descreve, explica e } \\
\text { prescreve; } \\
\text { Preocupa-se pelos } \\
\text { processos; } \\
\text { Transformações da } \\
\text { realidade social; } \\
\text { Aplicação linear }\end{array}$ & $\begin{array}{l}\text { Interpretativa, } \\
\text { compreensiva e } \\
\text { contextual. Contribui } \\
\text { com regras (não leis). } \\
\text { Como processo de } \\
\text { interacção social, } \\
\text { horizontal e dialógico }\end{array}$ & $\begin{array}{l}\text {-Orientada a transformar a } \\
\text { prática, iluminando e } \\
\text { dinamizando a acção. } \\
\text { Consciencializadora e } \\
\text { emancipadora no plano } \\
\text { social e individual }\end{array}$ \\
\hline
\end{tabular}

Data de registro 20/09/06

Data de aceite 29/09/06

Educ. e Filos., Uberlândia, v. 21, n. 41, p. 89-120, jan./jun. 2007. 